\title{
THE DESIGN OF VENEREAL DISEASES TREATMENT CENTRES
}

By I. W. HARRISON, D.S.O., M.B., F.R.C.P. (Ed.), Director of V.D. Department, St. Thomas's Hospital, Technical Adviser in V.D., Ministry of Health.

[Based on a lecture on the Design and Administration of the St. Thomas's Hospital V.D. Department, delivered at the Annual Meeting of the Medical Society for the Study of Venereal Diseases, July I4th, I934.]

\section{GeneraL}

EARLY in I9I5 I had to organise the treatment of Venereal Diseases in large numbers of military patients. The work had to be done by a comparatively small staff, and at once it became obvious that the design of the premises in which it was conducted would affect considerably its efficiency; alternatively, that the better the design in respect of labour saving, the smaller the staff required to maintain a suitable standard of efficiency.

Experience during the war amply bore out this view, and in I9I9, on taking up the post of Technical Adviser on Venereal Diseases to the Ministry of Health, whilst strongly urging that I ought to direct one of the Venereal Diseases Treatment Centres so that my recommendations would be up to date and practical, I insisted that the lay-out of the Centre should be in accordance with my design. These recommendations were carried into effect in the case of the Centre at St. Thomas's Hospital, and experience has justified them, for, although no other Centre in England and Wales is exactly like that at St. Thomas's Hospital, there are now a number in which the principles of its design are embodied, and it is admitted that they have proved very satisfactory in operation. I believe also that the principles have been approved by visitors from a number of other countries, in which they have subsequently been copied.

It is at least now admitted that the ordinary rooms of an out-patient department will not usually serve the 


\section{BRITISH JOURNAL OF VENEREAL DISEASES}

purposes of a V.D. Treatment Centre; that, in fact, premises specially designed for the work are necessary, and this article has been written in the hope that it may be useful to those who have to plan V.D. Treatment Centres in the future. Readers of this article may not agree with the plans described here, but to amend them would probably be easier for most workers than to construct completely new ones.

The following are the considerations that appear of chief importance in the planning of a V.D. Treatment Centre :-

(I) Cases of Venereal Disease require on first attendance an examination involving considerable exposure of the person. At the same time patients with Venereal Disease desire, and are entitled to, as much privacy under examination of the genital organs as do patients with other diseases. Indeed, it is probable that most of them are more sensitive in this respect than are other patients because of their feeling of shame.

(2) Cases of gonorrhœa periodically require examinations and treatment involving exposure of the genital organs, and the same considerations apply as in (I).

(3) Examinations of cases of Venereal Disease require preliminary unclothing of the patient and much reclothing afterwards. This unclothing and re-clothing should not involve waste of the time of the staff or take place in the presence of other patients.

(4) It is important that the staff should spend no more time than is absolutely necessary in obtaining instruments or in moving to and from patients, and that for any preparation and examination of microscopical specimens the necessary appliances should be as conveniently placed as possible.

(5) Communication between members of the staff should be as free and unimpeded as possible, and as much of the work as possible should be visible to the Director at any one time. Division of the staff, so that in a section for one sex some of the staff have to work in a place that is far removed from the main body of the clinic, should be avoided. This applies particularly to irrigation, facilities for which have often been placed in a room situated a considerable distance from the main clinic, with the result that one attendant has been kept wholly employed on work that was insufficient to occupy 


\section{VENEREAL DISEASES TREATMENT CENTRES}

more than a fraction of his time, and, moreover, this attendant has been insufficiently under supervision, owing to the inconvenience of visiting his post.

(6) The Centre should be so arranged that intermediate treatment, such as irrigations, dressings, etc., by or

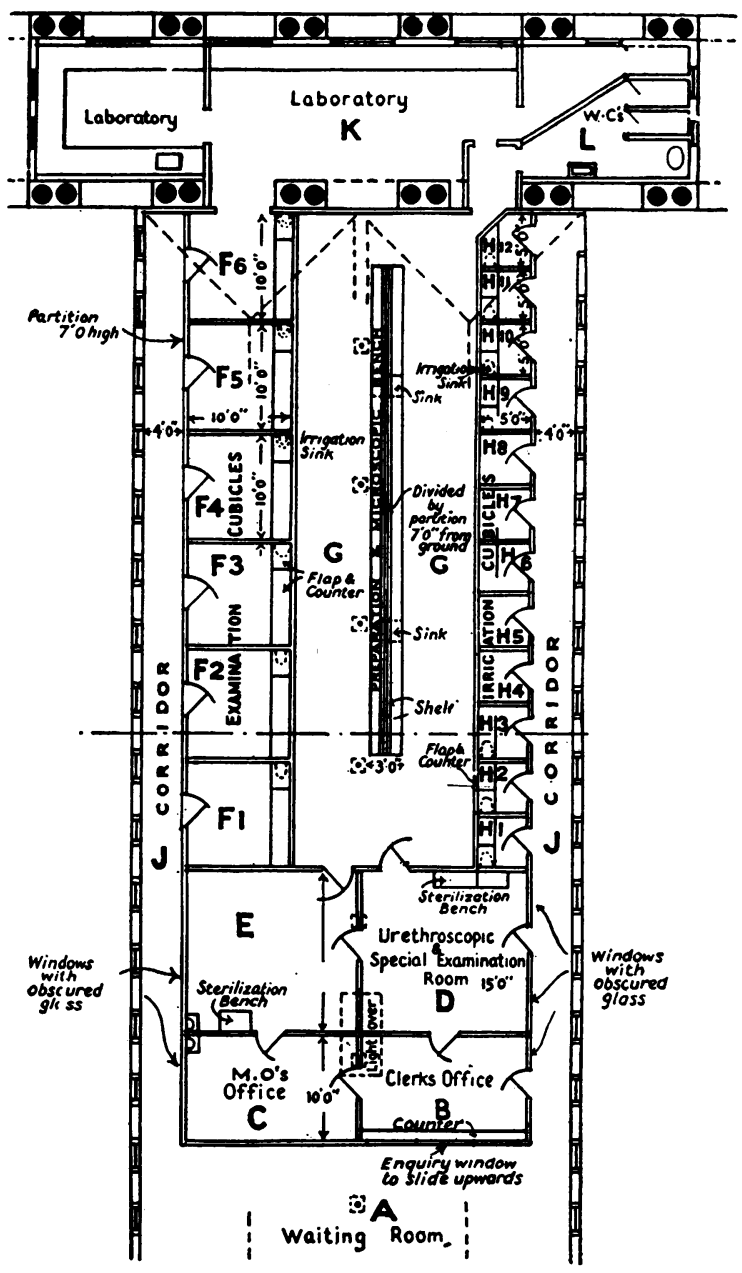

FIG. I.

under the supervision of the nurses, can be available for both sexes at the same hours.

(7) The approach to the Centre should be as little ad hoc as possible, and certainly if it is necessary to use any path or passage that leads only to the Centre, such an approach should not be used by both sexes, because 


\section{BRITISH JOURNAL OF VENEREAL DISEASES}

this is likely to lead to undesirable assignations, or else to blackmail of women and girls attending the Centre.

In the Centre at St. Thomas's Hospital the above principles have been observed in the following manner. The number of cases dealt with by the Centre is sufficiently large to justify construction of separate premises for males and females respectively. The section for males is illustrated in Fig. I; that for females is somewhat different from the design illustrated in Fig. I, but it embodies the same principles.

Fig. I may perhaps be understood most easily by

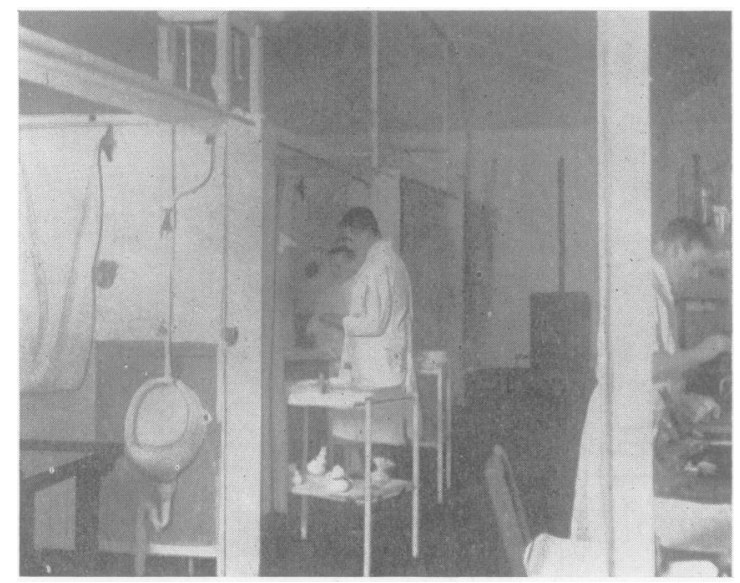

FIG. 2.

describing the movements of patients and staff in the building of which it is a plan.

A new male patient enters the waiting-room A from the main corridor of the hospital, and immediately goes to an office window $\mathrm{B}$, where he is directed to proceed along the corridor on the left, marked $\mathrm{J}$, and enter one of the cubicles, FI to F6, that is named to him. The design of these cubicles will be clear from a study of Figs. 2 and 3 and of the examination cubicles illustrated in Fig. 9. This shows that each cubicle is shut off from its neighbours and from the patients' corridor $J$ by partitions, but is open to a space designated as $G$ in Fig. I, and as service and general room in Fig. 9, being separated therefrom by $(a)$ a curtain and $(b)$ an oblong table or counter 3 feet high on which is a mattress. It will be obvious that, whilst the patient in the cubicle 


\section{VENEREAL DISEASES TREATMENT CENTRES}

cannot be seen by other patients, who are not allowed to enter the "Service Space" G, he is quite easily accessible to the staff working in the service space, as shown in

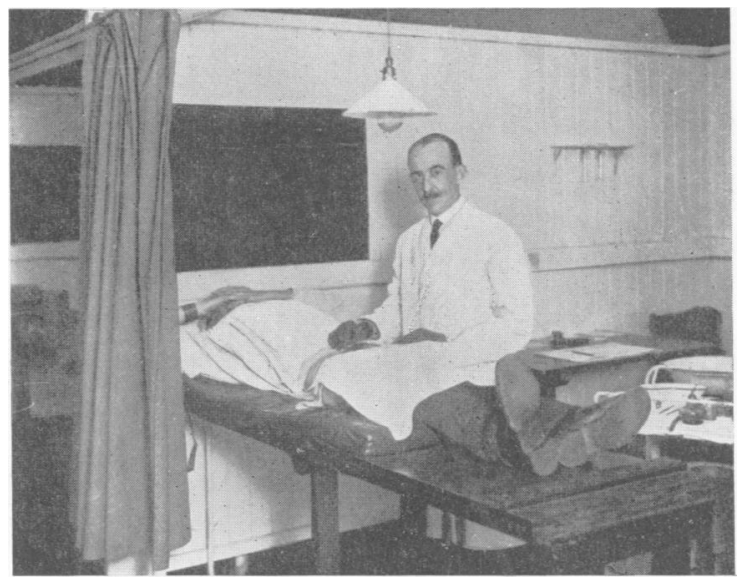

FIG. 3.

Fig. 2 and in Fig. 4, which illustrates a cubicle in the section for females.

The patient's particulars are taken by a clerk, who

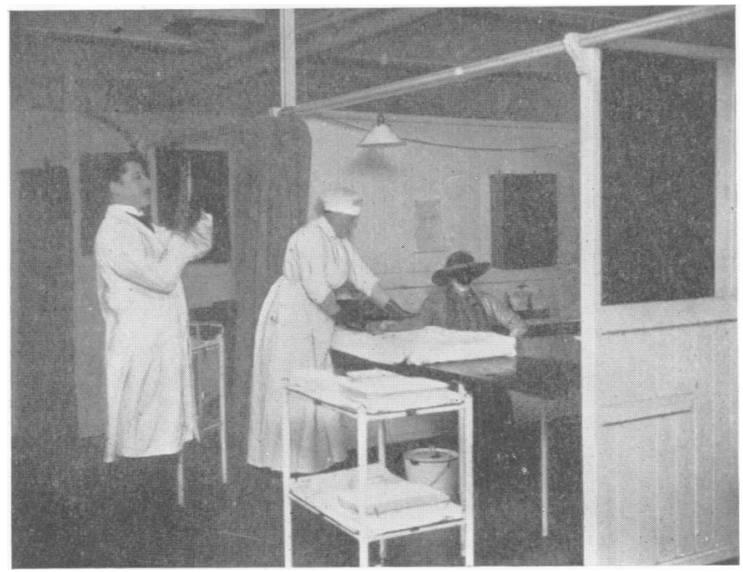

FIG. 4.

then draws the curtain, thus intimating to the medical staff that a new patient is present. A medical officer examines the patient in the cubicle, which is self-contained in respect of appliances for obtaining specimens, 


\section{BRITISH JOURNAL OF VENEREAL DISEASES}

and any of these requiring microscopical examination are taken a few feet across the service space to the work-

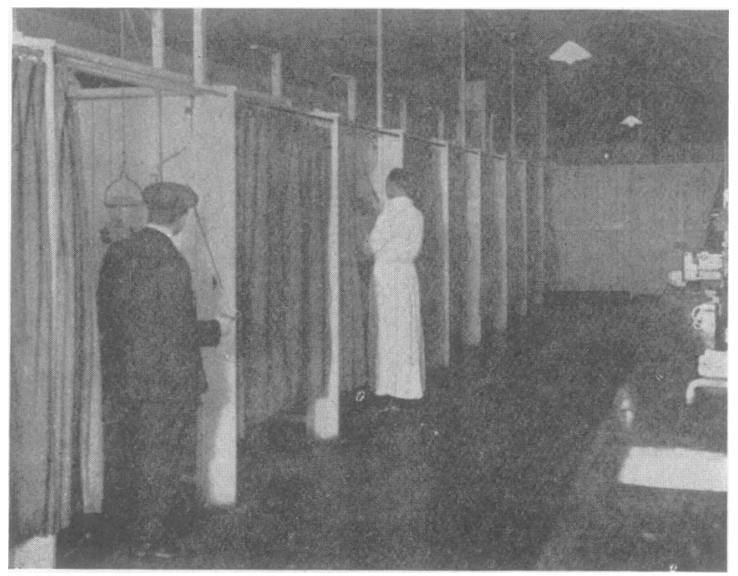

FIG. 5.

bench shown on the right in Fig. 2. For any necessary injection, or other operation, the appliances are carried on surgical tables, and the medical officer administers

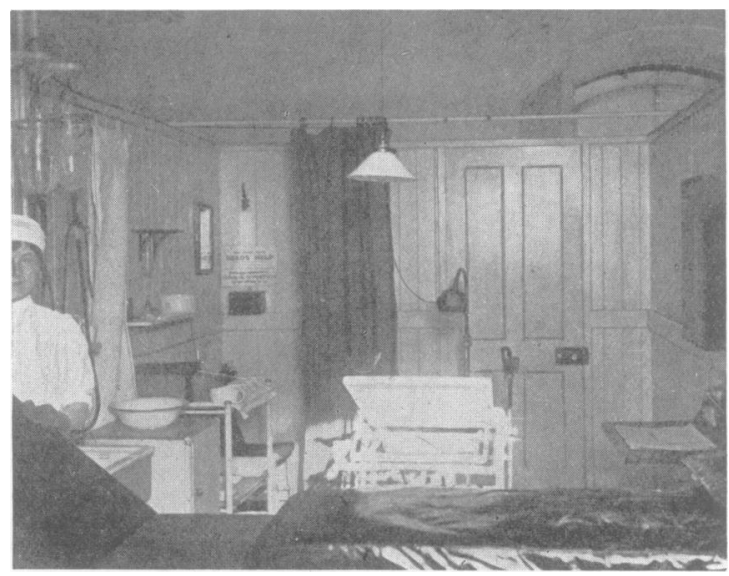

FIG. 6.

treatment as far as possible from the service space, as shown in Figs. 2 and 4.

It will be seen that, owing to the provision of a number of cubicles, the medical officer's time is not wasted waiting for the patient to unclothe, that the patient's 228 


\section{VENEREAL DISEASES TREATMENT CENTRES}

privacy is secured, and that no time is lost in collecting appliances for dealing with the patient, since appliances other than those for microscopical tests can be moved rapidly from one cubicle to another. It will be seen also that the Director of the clinic can observe from one point a large proportion of the work of the clinic.

After his first visit a patient with gonorrhœa is asked to attend daily for irrigation. Each time he attends for this purpose he reports at the office and receives a card, on which the prescription for the irrigating lotion is written and attendances are stamped. $\mathrm{He}$ takes the card by the corridor $\mathrm{J}$ on the right in Fig. I and enters the first vacant cubicle he can find. Again, the cubicle opens on the service space $G$, and the patient finds

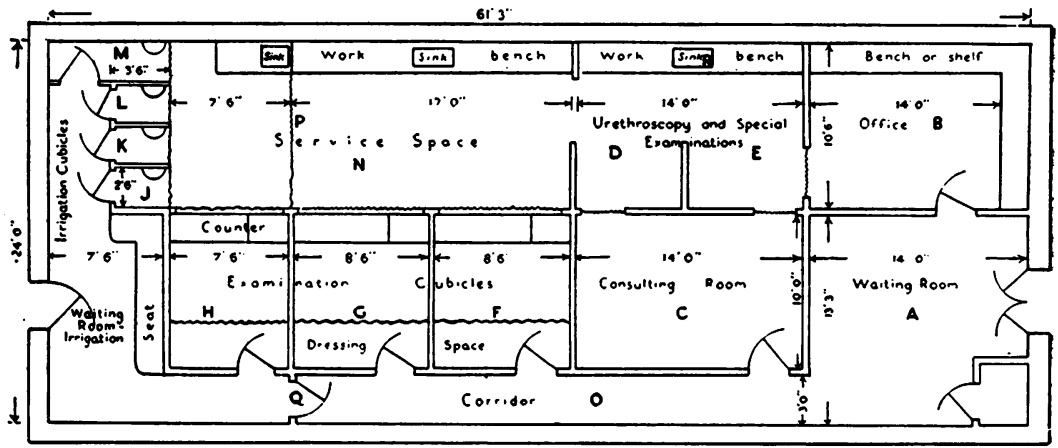

FIG. 7 .

himself in the presence of an attendant, as shown in Fig. 5. The attendant takes the card, reads the instructions as to the kind of irrigation required, and carries a measured amount of the concentrated lotion with a sterile nozzle to the cubicle, as is shown being done in Fig. 5 . Each cubicle is fitted with hot and cold water taps, by which the irrigator vessels are filled. The irrigation sink in each cubicle is set on the right-hand partition as one faces the cubicle from the service space and fairly close to the service space edge of the partition. The advantages of this are fourfold, viz. : (I) The patient's side is towards the attendant, who can therefore supervise the irrigation properly. (2) The patient's right hand is towards the service space ; therefore, if he requires help in irrigation, the attendant standing on his right side is still in the service space. (3) The position is the nearest to the attendant's 


\section{BRITISH JOURNAL OF VENEREAL DISEASES}

work-bench, and therefore requires the shortest walk. (4) The cubicle need be only 2 feet 6 inches or even 2 feet 3 inches broad, and four cubicles with irrigation sinks hung on partitions as shown can easily be accommodated in a length of ro feet, an important consideration when space is limited.

The patient with gonorrhœa is not allowed to continue irrigation for longer than a week without seeing the medical officer. For this purpose he is sent to room $\mathrm{C}$,

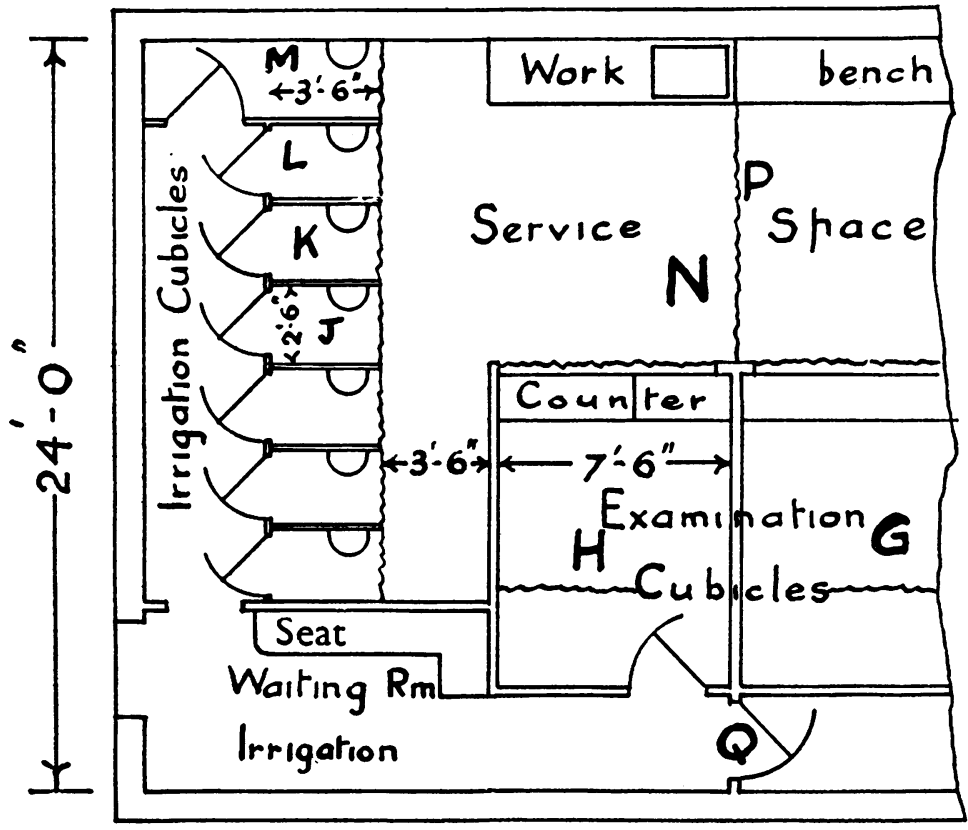

FIG. 8.

which is entered from the corridor by a door that is not shown. In time it becomes clear that a more detailed examination is necessary, and the patient is asked to come at a time when the medical officer is free for long individual examinations, such as urethroscopy. These examinations are carried out in the room marked $\mathrm{D}$, the design of which has now been improved, as will be shown later.

The patient with syphilis comes regularly for injections. At each visit he is sent first to cubicle FI for a urine test, and then goes to room $\mathrm{E}$, where a medical officer examines him and decides as to his fitness for the next injection in 


\section{VENEREAL DISEASES TREATMENT CENTRES}

the course. All being well, the patient is sent to one of the cubicles, $\mathrm{F}_{2}$ to $\mathrm{F}_{5}$, already described and receives the intravenous injection, as is shown about to be done in Fig. 4. The intramuscular injection is given at the same time in the cubicle.

The examination cubicles in the section for females are similar to those in the section for males, but contain more furniture, as can be seen in Fig. 6. At the back of each a dressing space is screened off by a curtain, which can be pushed to one side when the patient is on the table.

A plan of a treatment centre which embodies the same

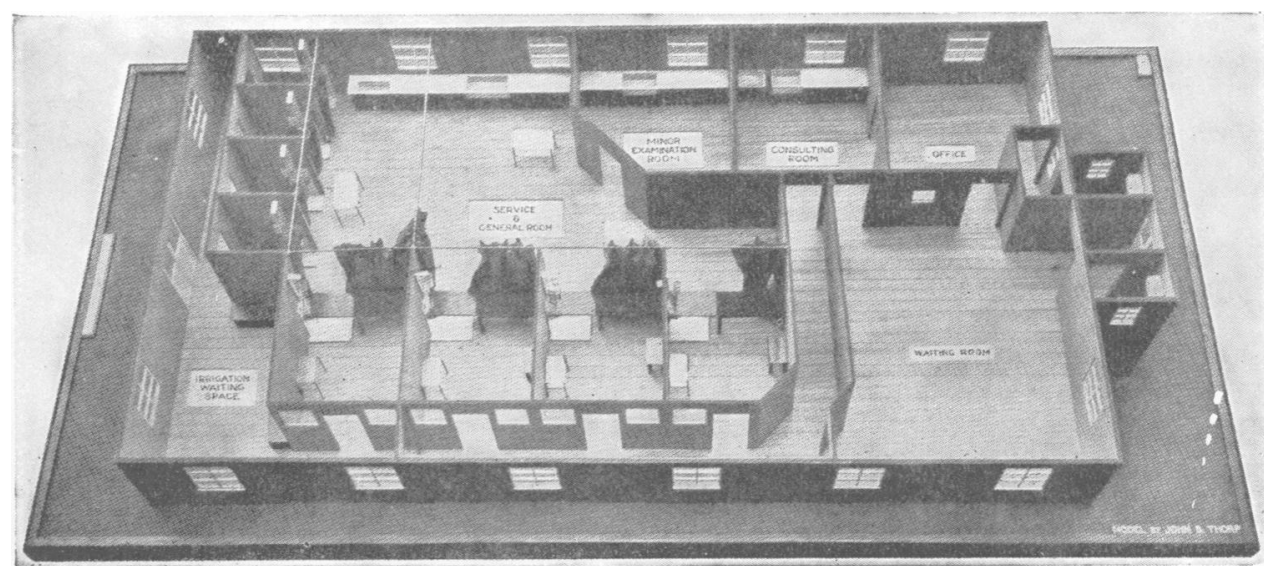

FIG. 9.

principles and is suitable for a considerably smaller turnover of cases is shown in Fig. 7. In this it will be seen that, as in the parent design, the cubicles are entered from a patients' corridor and open on to a service space. In this plan the irrigation cubicles are set at right angles to the others, and it will be seen that the urethroscopy room is rather different from that shown in Fig. I. It is partly divided into two, D and $\mathrm{E}$, by a short partition, and in each half is an examination table. The intention is that a patient in one half can be getting ready for examination, or to go away, whilst a patient in the other half, out of his sight, is under examination; thus the time of the staff is not wasted waiting for patients to unclothe or to re-clothe. The examination cubicles, F, $G$ and $H$, each have a dressing space screened off, as in 


\section{BRITISH JOURNAL OF VENEREAL DISEASES}

Fig. 6, because $\mathrm{F}$ and $\mathrm{G}$ at least are intended for examination of females. The design is intended for the holding of sessions dealing with males and females respectively at different hours. It provides also, however, for intermediate treatment of both sexes at the same time and for intermediate treatment of males to be carried out during sessions for females. In either of these cases a curtain at $\mathrm{P}$ is drawn and a door at $\mathrm{Q}$ is closed, and males enter at the door on the left. In some cases it may be advisable to provide more irrigation cubicles than are shown in Fig. 7. In these the design can be modified on the lefthand side, as is shown in Fig. 8, the centre being lengthened by 3 feet 6 inches. On the other hand, the probable turnover of cases may not justify provision of a centre so large as that shown in Fig. 7 ; in this case cubicle $\mathrm{F}$ and even $\mathrm{G}$ could be omitted. Another design is shown in Fig. 9, which does not, however, appear to be so convenient as the others, and is reproduced here only for the purpose of making the meaning of Figs. I, 7 and 8 clearer to those who are not skilled in the reading of plans. 